\title{
Urethro-urethral fistula: A rare cause of post-TURP incontinence
}

\author{
H. Krishna Moorthy, MS, MCh; Biju S. Pillai, MS, DNB
}

Lourdes Hospital, Kochi, India

Cite as: Can Urol Assoc J 2014;8(11-12):e916-7. http://dx.doi.org/10.5489/cuai.2269

Published online December 15, 2014.

\section{Abstract}

Prostatic abscess rarely follows acute prostatitis and can sometimes lead to a fistula by breaking into the prostatic urethra, peri-rectal tissues, the perineum, or the rectum. We report a case of a prostatic abscess tracking into the bulbar urethra after a transurethral resection of the prostate. This created a fistula, mimicking a urethral duplication and leading to urinary incontinence.

\section{Case report}

A 56-year-old male patient, and known diabetic for the past 5 years, presented with a 5-day fever and acute urinary retention. He had a history of failed traumatic catheterization, which was attempted elsewhere. He had recurrent episodes of urinary tract infections in the past 2 months and was treated with oral antibiotics. Clinical examination revealed a distended bladder with tender grade 2 prostatomegaly. He was catheterized with difficulty and started on parenteral antibiotics. Ultrasound scan of the abdomen revealed prostatomegaly with the presence of a prostatic abscess of about $2.5 \times 2 \mathrm{~cm}$ in size in the right lobe and multiple small abscesses in the left lobe of the prostate. Since the patient continued to have intermittent fever and the abscess was not resolving even after 5 days of parenteral antibiotics, he underwent a cystoscopic de-roofing of the abscess with a transurethral resection of the prostate. Percutaneous drainage of the abscess was not considered as the patient was obese and the abscess was deep-seated posteriorly.

During the cystoscopy, a false passage was noted in the bulbar urethra on the posterior wall, due to prior traumatic catheterization and there were multiple abscesses in the prostate. The postoperative period was uneventful. The catheter was removed on postoperative day 4 and the patient began voiding satisfactorily with mild urge incontinence.
The patient then presented 3 weeks after surgery with complaints of continuous urinary incontinence, which progressively increased in intensity over the past week. Physical examination was normal, with dribbling of urine noted even when the patient was lying down. The patient was managed conservatively with antibiotics and anticholinergics. The patient was not willing to undergo a cystoscopy and did not come for follow-up. From another centre, he was prescribed a penile clamp to control his incontinence.

Three months after surgery, the patient came back for further evaluation because of the persistent incontinence. An ultrasound of the abdomen was normal. During the cystoscopy, a small epithelized track was seen in the ventral aspect of bulbar urethra (Fig. 1) leading into the prostatic fossa just proximal to the veru montanum. The normal urinary passage could also be seen separately. The external sphincter and bladder mucosa were normal. A guidewire passed through the fistula from the distal end and emerged out of the proximal end of the fistula in the prostatic fossa (Fig. 2). A retrograde urethrogram (RGU) was done with the patient on the table and the catheter kept in the normal urethral passage; it mimicked a urethral duplication of the Effman's type 2B classification (Fig. 3).

The patient underwent excision of the urethro-urethral fistula with urethroplasty and a gracillis muscle was wrapped around at a later date. After surgery, the patient became continent with minimal stress urinary incontinence.

\section{Discussion}

Prostatic abscess rarely follows acute prostatitis, with a reported incidence of $0.5 \% .^{1}$ Untreated prostatic abscesses may burst into the prostatic urethra, peri-rectal tissue, the perineum, or the rectum to form a fistula. Treatment of prostatic abscesses includes broad spectrum antibiotics based on urinary antibiogram. ${ }^{2}$ In patients unresponsive to conservative management, drainage of the prostatic abscess (transrectal ultrasound guided aspiration, digital guided aspiration, transurethral resection of prostate, transurethral 


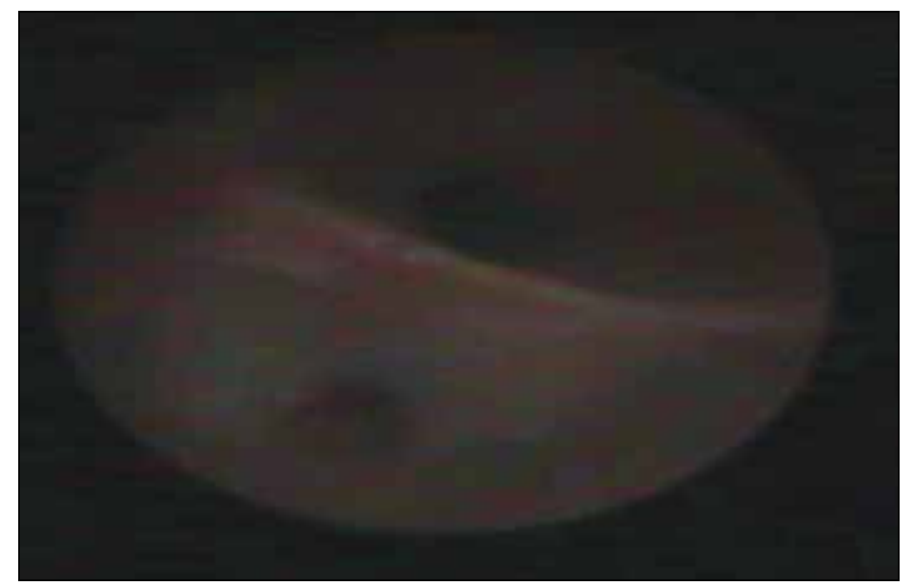

Fig. 1. A small epithelized track seen in the ventral aspect of bulbar urethra.

incision of the abscess cavity or open drainage) may be needed. ${ }^{3,4}$

Acquired urethral fistula is rare and usually occurs as a result of infection, trauma, or surgery. ${ }^{5}$ The various options for urethral fistula repair include primary closure via Thiersch-Dupley urethroplasty, flap urethroplasty, pedicle island tube, or onlay urethroplasty. ${ }^{6}$

In our case, the prostatic abscess may have created a false passage in the bulbar urethra due to the traumatic catheterization; this created a urethro-urethral fistula, mimicking urethral duplication of the Effman's type 2B classification. ${ }^{7}$ The fistula bypassed the external urinary sphincter and caused urinary incontinence. To avoid operative drainage of the abscesses, prostatic abscesses should be diagnosed and treated early; percutaneous drainage should be attempted if possible and drainage should be the last resort. A literature search did not reveal previous reports of a similar case.

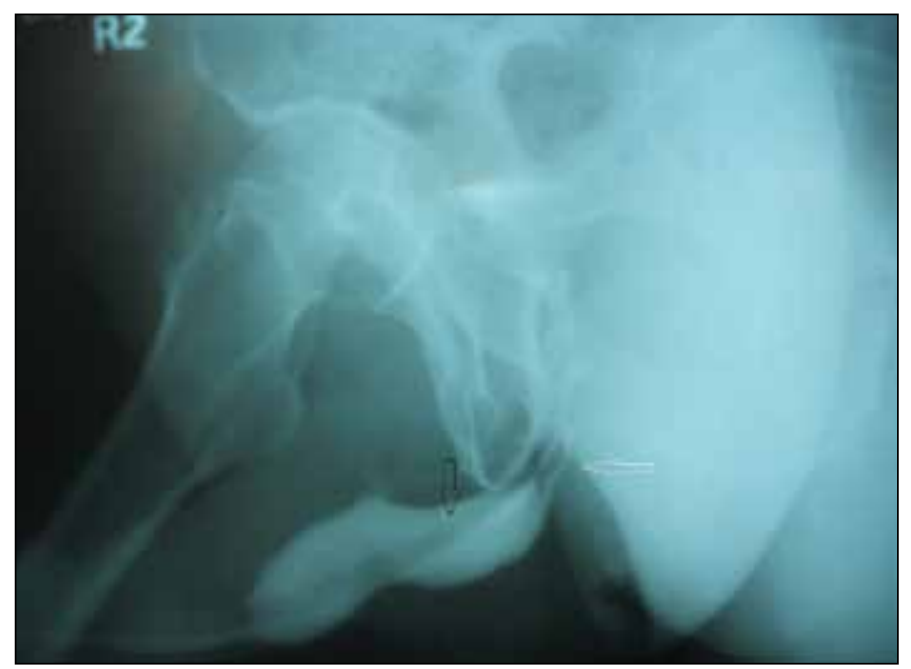

Fig. 3. A retrograde urethrogram showing a urethra-urethral fistula.

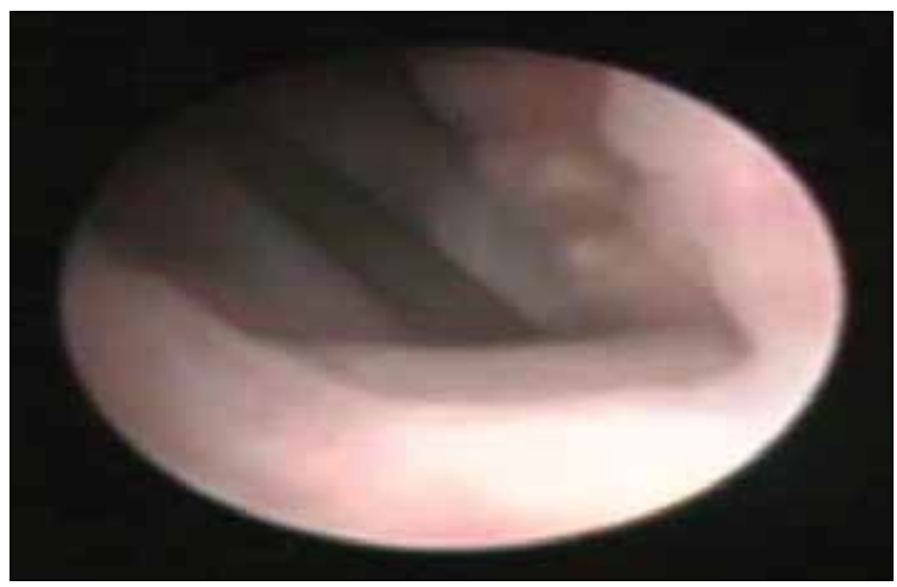

Fig. 2. Guidewire emerging out of the proximal end of fistula in the prostatic fossa.

Competing interests: Authors declare no competing financial or personal interests.

This paper has been peer-reviewed.

\section{References}

1. Ludwig M, Schroeder-Pritzen I, Schiefer HG, et al. Diagnosis and therapeutic management of 18 patients with prostatic abscess. Urology 1999;53:340-5. http://dx.doi.org/10.1016/S0090-4295(98)005032

2. Vinheas AFJ. Diagnosis and treatment of prostatic abscess. Clinical Urol Int 2003;29:30-4.

3. Basiri A, Javaherforooshzadeh A. Percutaneous drainage for treatment of prostatic abscess: Case report. Urol J 2010;7:276-80.

4. Kinahan TJ, Goldenberg SL, Aizen AS, et al. Transurethral resection of prostatic abscess under sonographic guidance. Urology 1991;37:475-7. httr://dx.doi.org/10.1016/0090-4295(91)80117-P

5. Lau JT, Ong GB. Subglandular urethral fistula following circumcision: Repair by the advancement method. J Urol 1981;126:702-3.

6. Agarawal P. Congenital anterior urethrocutaneous fistula revisited. Ind J Plast Surg 2004;37:64.

7. Effman EL, Lebowitz RL, Colodny AH. Duplication of the urethra. Radiology 1976;119:179-85. http:// dx.doi.org/10.1148/119.1.179

Correspondence: Dr. Krishna Moorthy, Lourdes Hospital, Kochi, India; dr.moorthy65@gmail.com 